\title{
Diet-gene interactions between dietary fat intake and common polymorphisms in determining lipid metabolism
}

\author{
By Dolores Corella
}

\author{
Genetic and Molecular Epidemiology Unit. Department of Preventive Medicine and Public Health, \\ University of Valencia. Avda. Blasco Ibáñez, 46010-Valencia and CIBER Fisiopatología \\ de la Obesidad y Nutrición (CB06/03) as an initiative of the ISCIII, Spain \\ Corresponding author: dolores.corella@uv.es
}

\section{RESUMEN}

\begin{abstract}
Interacciones dieta-genotipo entre el consumo de grasas y polimorfismos comunes determinando el metabolismo lipídico.
\end{abstract}

Las recomendaciones dietéticas actuales referentes al consumo de grasas en la dieta han sido realizadas sin tener en cuenta las posibles diferencias genéticas de las personas que podrían ser las responsables de las diferentes respuestas interindividuales que frecuentemente se observan ante la misma dieta. La presencia de variabilidad genética ha sido puesta de manifiesto para todos los genes relacionados con el metabolismo lipídico, por lo que existe un ingente número de genes y de variantes genéticas para ser incluidas en los estudios sobre interacciones dieta-genotipo en el ámbito específico del consumo de grasas y aceites. Se revisarán algunos ejemplos sobre interacciones grasa-genotipo. Estas interacciones incluyen: la interacción entre el consumo de grasa total y el polimorfismo $-514 \mathrm{C} / \mathrm{T}$ en el promotor del gen de la lipasa hepática determinando las concentraciones de colesterol ligado a lipoproteínas de alta densidad (c$\mathrm{HDL}$ ); la interacción entre el consumo de ácidos grasos poliinsaturados y el polimorfismo $-75 \mathrm{G} / \mathrm{A}$ en el promotor de gen APOA1 en las concentraciones plasmáticas de c-HDL; la interacción entre los ácidos grasos poliinsaturados y el polimorfismo L162V en el gen PPARA determinando las concentraciones plasmáticas de triglicéridos y de apolipoproteína C-III; la interacción entre el polimorfismo $-1131 \mathrm{~T}>\mathrm{C}$ en el promotor del gen de la APOA5 determinando el metabolismo de los triglicéridos. Aunque se han publicado cientos de estudios dieta-genotipo en el ámbito del metabolismo lipídico, el nivel de evidencia científica todavía es bajo para realizar recomendaciones nutricionales a la población, por lo que se requiere mucha más investigación nutrigenética.

PALABRAS CLAVE: Dieta - Genes - Interacción - Lípidos - Nutrigenética - Polimorfismos.

\section{SUMMARY}

Diet-gene interactions between dietary fat intake and common polymorphisms in determining lipid metabolism.

Current dietary guidelines for fat intake have not taken into consideration the possible genetic differences underlying the individual variability in responsiveness to dietary components. Genetic variability has been identified in humans for all the known lipid metabolim-related genes resulting in a plethora of candidate genes and genetic variants to examine in diet-gene interaction studies focused on fat consumption. Some examples of fat-gene interaction are reviewed. These include: the interaction between total intake and the $-514 \mathrm{C} / \mathrm{T}$ in the hepatic lipase gene promoter in determining high-density lipoprotein cholesterol (HDL-C) metabolism; the interaction between polyunsaturated fatty acids (PUFA) and the $-75 \mathrm{G} / \mathrm{A}$ polymorphism in the APOA1 gene plasma HDL-C concentrations; the interaction between PUFA and the L162V polymorphism in the PPARA gene in determining triglycerides and $\mathrm{APOC} 3$ concentrations; and the interaction between PUFA intake and the $-1131 \mathrm{~T}>\mathrm{C}$ in the APOA5 gene in determining triglyceride metabolism. Although hundreds of diet-gene interaction studies in lipid metabolism have been published, the level of evidence to make specific nutritional recommendations to the population is still low and more research in nutrigenetics has to be undertaken.

KEY-WORDS: Diet - Genes - Interaction - Lipids Nutrigenetics - Polymorphisms.

\section{INTRODUCTION}

Currently, there is a lot of controversy about which is the best diet to prevent or treat disease (Steinberg D, 2005; Getz et al., 2007; Rioux et al., 2007). Cardiovascular diseases are the leading cause of death in the World whether living in rich or in poor countries. The implication of plasma lipids in the atherosclerotic process that determines cardiovascular diseases has been known for many years (Le and Walter, 2007). However, lipid metabolism is a complex process in which different enzymes, receptors, transporters, lipoproteins, etc., are involved. Thus, from food intake to the plasma lipid concentrations detected, a great number of steps take place, than can differ considerably among individuals. It is therefore not surprising that many studies have been carried out with differing results when the relationship between diet and plasma lipids has been investigated (Katan, 2005; Brunner et al., 2007). Arising from this controversy several eating pyramids have been proposed: The healthy eating pyramid, the Mediterranean diet pyramid, the United States Department of Agriculture (USDA) pyramid, the World Health Organization (WHO) pyramid, etc (Chiuve and Willet, 2007). For several decades, the debate on diet and lipid metabolism and cardiovascular diseases has been dominated by the classic "diet-heart" hypothesis centered in the concept of the promotion of a low-fat diet 
in preventing the adverse effect of dietary saturated fatty acids (SFA) and cholesterol on cardiovascular risk. Therefore, reduction of fat intake has been the main focus of national and international public health recommendations for risk reduction. However, this approach has been increasingly criticized for being too simplistic. Moreover, the studies on which current nutritional recommendations are based, were conducted without taking into account possible genetic differences in response. However, in a normal situation, there is a variability in the individual responses following a dietary intervention to decrease total cholesterol concentrations or to decrease other plasma lipid parameters. Depending on their response, individuals are called: hypo-responders, normoresponders or hyper-responders. As an example of inter-individual variations in the change in lipid profile as a response to the same diet we have the paper of Schaefer et al. (1997) in which, after intervention with the National Cholesterol Education Program Step 2 diet, a wide variability in plasma low-density lipoprotein cholesterol (LDLC), high-density lipoprotein cholesterol (HDL-C) and triglyceride (TG) concentrations in response to diet was observed. Can individual differences in diet response be explained by variations in the genome? If we assume diet-gene interaction, can nutritional recommendations in lipid metabolism be made regardless of genes? To answer these questions, much more research has to be undertaken on diet-gene interaction. Hence, there is a need to know which specific genetic variations are those that modify the effects of diet on lipid metabolism and the risk of disease. We have to investigate: which genes are relevant; how many variations in each gene must be studied and which specific dietary components are interacting with each genetic variation to determining the specific phenotype.

In the last few years a new discipline has emerged: Nutrigenetics. It examines the effect of genetic variation on the interaction between diet and disease. This includes identifying gene variants associated with differential responses to nutrients. Thus, the goal of nutrigenetics is to generate recommendations regarding the risks and benefits of specific diets or dietary components for the individual. It has also been termed personalized nutrition or individualized nutrition (Ordovas and Corella, 2004). Although the initial studies have focused on single nucleotide polymorphisms (SNP) to measure DNA variation (genotypic or haplotypic approaches), in the last few years, new types of DNA variation such as copy number variation, are increasing in interest (Rodriguez-Revenga et al, 2007).

\section{SOME EXAMPLES OF FAT-GENE INTERACTIONS IN DETERMINING LIPID METABOLISM}

Dietary fats have been the component of the diet that has been more studied in nutrigenetic studies.
There are hundred of papers that report the presence of a statistically significant interaction between dietary fatty acids and different SNP in candidate genes in determining plasma lipid concentrations. In an excellent systematic review (from 1966 to 2002), Masson et al. (2003) identified 74 relevant articles on dietary intervention studies that had measured the lipid and lipoprotein response to dietary intervention in different genotype groups and 17 reviews on gene-diet interactions. They analyzed the published articles according to seven groups of genetic locus: Apolipoprotein (apo) A-I, C-III, and A-IV cluster; ApoB; ApoE; Enzymes (lipoprotein lipase, hepatic lipase, and cholesterol- $7 \alpha$-hydroxylase); LDLreceptor gene; and other genes, including CETP, fatty-acid-binding protein (FABP), and neuropeptide $Y$ (NPY). At each locus, one or more polymorphisms were included, and the mainly short-term response to a defined dietary intervention [i.e., high-fat diet versus a low fat diet; high-saturated fatty acids (SFA) versus highpolyunsaturated fatty acids (PUFA); highmonounsaturated fatty acids (MUFA) versus lowMUFA, etc.]. After a comparative analysis of the individual findings, Masson et al., (2003) conclude that there is evidence to suggest that variations in genes for apo A-I (APOA1), apo A-IV (APOA4), apo $B(A P O B)$, and apo $E$ (APOE) contributes to the heterogeneity in the lipid response to dietary intervention. However, the effects of the reported gene-diet interactions are not consistently seen and are sometimes conflicting. There are several possible reasons to explain the discrepancies between studies analyzing the modulation of the lipid response to a similar dietary intervention by the same polymorphism. One of them relates to the small sample sizes used by most researchers, which results in a lack of statistical power, particularly for low allele frequencies. Another important reason is the heterogeneity of the subjects included in every study, differing in gender, age, disease status, medical treatment, etc. In addition, the length and the composition of the dietary treatment greatly vary between studies. Therefore, for future work it is necessary to standardize a minimum set of variables to be considered in the design of intervention studies in order to replicate into the same conditions that assure a good comparison in results of different studies.

As more detailed studies, various examples of fat-gene interactions in determining lipid metabolism that we have described over recent years, are presented.

\subsection{Hepatic lipase gene variation and total fat intake in determining HDL-C}

Hepatic lipase plays a major role in lipoprotein metabolism as a lipolytic enzyme that hydrolyzes triglycerides and phospholipids in chylomicron 
remnants, intermediate-density lipoproteins (IDL), and HDL. Patients with hepatic lipase deficiency present with hypercholesterolemia or hypertriglyceridemia and accumulate $\beta$-very low-density lipoproteins (VLDL), chylomicron remnants, IDL, triglyceride-rich LDL, and HDLs. Hepatic lipase is also an important determinant of HDL concentration, converting the phospholipidrich HDL2 to HDL3 during reverse cholesterol transport. Four common SNPs $(-763 \mathrm{~A}>\mathrm{G}$; $-710 \mathrm{~T}>\mathrm{C}$; $-514 \mathrm{C}>\mathrm{T}$ and $-250 \mathrm{G}>\mathrm{A}$ ) on the promoter of the hepatic lipase gene (LIPC), appear to be in total linkage disequilibrium and define a unique haplotype which has been demonstrated to be functional. Ordovas et al., (2002) have found a strong interaction between the $-514 \mathrm{C}>\mathrm{T}$ LIPC polymorphism and dietary fat intake, and HDLrelated measures in 1020 men and 1110 women participating in the Framingham Study. This genenutrient interaction was highly significant and with a strong dose-response effect in determining HDL-C concentrations $(P<0.001)$, large $H D L$ subfraction $(P<0.001)$, and HDL size $(P=0.001)$ in both men and women. Accordingly, the $\mathrm{T}$ allele was associated with significantly greater HDL-C concentrations and particle size only in subjects consuming $<30 \%$ of energy from fat. When total fat intake was $\geqslant 30 \%$ of energy, mean HDL-C concentrations and HDL-particle size were lowest among those with the TT genotype, and no differences were observed between CC and CT individuals. This gene-diet interaction was further examined in a multiethnic Asian population from Singapore participating in the National Health Survey carried out by the Ministry of Health. This sample consisted of 1324 Chinese, 471 Malays and 375 Asian Indians (Tai et al., 2003). Tai et al., (2003) found a highly significant interaction $(P=0.001)$ between the $-514 \mathrm{C}>\mathrm{T}$ polymorphism in the LIPC and total fat intake in determining $\mathrm{TG}$ concentration and the $\mathrm{HDL}-\mathrm{C} / \mathrm{TG}$ ratio $(P=0.001)$ in the three ethnic groups. Thus, TT subjects showed higher TG concentrations only when fat intake was higher than $30 \%$ of total energy. This interaction also showed a dose-response effect on triglyceride concentrations depending on the amount of total fat consumed $(P=0.035)$. For HDL-C concentrations, the genediet interaction was significant $(P=0.015)$ only in subjects of Indian origin suggesting additional mechanisms to be explored. Further studies carried out in other populations have reported controversial results. Thus, Zhang et al., (2005) in a study carried out in 780 diabetic men participating in the Health Professionals Follow-Up Study, described a statistical significant interaction between the LIPC polymorphism and fat intake. However the effects were in the opposite direction. They found that the association between the LIPC $-514 \mathrm{C}->\mathrm{T}$ polymorphism and plasma HDL-cholesterol concentrations varied according to self-reported intakes of total, saturated, monounsaturated, and trans-fats. A significantly higher HDL-cholesterol concentration in relation to the $\mathrm{T}$ allele was confined to men with higher intakes of total, saturated, or monounsaturated fat. One of the limitations of this study is the small sample size, taking into account the low prevalence of subject with the TT genotype in the White population (about $3.5 \%$ ).

On the other hand, Nettleton et al., (2007) carried out a study in 11,806 (8897 Whites/ 2909 African Americans) participating in the Atherosclerosis Risk in Communities (ARIC) study. This study consisted of a cohort of men and women, aged 45-64, from four communities in the United States (Forsyth County, North Carolina; Jackson, Mississippi; Northwest Minneapolis suburbs, Minnesota; Washington County, Maryland). They found that in Whites, the relation between the LIPC polymorphism and HDL-C was not modified by dietary fat intake. However, a statistically significant interaction was found in African Americans. In African Americans women, when percent total fat intake was low, HDL-C concentrations in CC subjects were approximately $5 \mathrm{mg} / \mathrm{dL}$ lower than in CT and TT subjects; however, when percent total fat intake was high, HDL-C concentrations were similar between $\mathrm{CC}$ and TT homozygotes. Ethnic differences in gene expression or ethnic in dietary intake may be partly responsible for these discordant findings. Moreover, the $-515 \mathrm{C}>\mathrm{T}$ LIPC polymorphism may be in strong linkage disequilibrium with another polymorphism in African Americans but not in Whites, therefore, serving only as a marker of another causal polymorphism. Ethnic differences in dietary patterns and food selection may also complicate interpretation since it is likely that food sources of fats and other nutrients differ between men and women and between Whites, African Americans and Asians, providing an additional set of potential confounders.

\subsection{PUFA interaction with PPARA, PPARG, APOA1 and APOA5 gene variation}

In the search for other food components that could be susceptible to showing gene-diet interactions we selected PUFA as they are important modulators of gene expression. The molecular mechanisms of PUFA regulation of gene expression are still poorly understood, although progress has been made in the last few years. PUFA suppression of several hepatic genes was shown to be due largely to a decrease in the rate of gene transcription. Peroxisome proliferatoractivated receptors (PPARs) are transcription factors that play a major role in regulating several genes involved in lipid metabolism (Guri et al., 2006). It has been shown that PUFA can modulate the expression of these nuclear transcription factors. PPAR-alpha $(A)$ is a ligand-activated transcriptional factor that belongs to the family of nuclear receptors. PPARA regulates the expression of genes involved in fatty acid beta-oxidation and is a major regulator of energy homeostasis. Fibrates 
are PPARA agonists and have been used to treat dyslipidemia for several decades because of their TG lowering and HDL-C elevating effects. Several common genetic variants in the PPARA have been described. One of these polymorphisms, consisting of a G484C transversion at the first base of codon 162 , creates a missense mutation that alters leucine to valine (L162V) and has functional consequences on receptor activity. Interestingly, it was shown that the effect of the L162V polymorphism on the transcriptional activation associated with ligand binding to PPARA depends on the concentration of the ligand to which it is exposed. A wide range of compounds were identified as natural or synthetic ligands for PPARA. Fatty acids, mainly PUFA and PUFA-derived compounds, are natural ligands of PPARA (Jump, 2002). Thus, we hypothesized that dietary PUFA can interact with the PPARA-L162V polymorphism in determining the effects of this polymorphism on plasma lipid concentrations. We carried out a dietgene interaction study in 1003 men and 1103 women who participated in the Framingham Offspring cohort (Tai et al., 2005). PUFA intake ranged from 2.0 to $16.5 \%$ of total energy intake in men and from 1.2 to $13.7 \%$ of total energy intake in women. The mean intake of dietary PUFA for the whole population was $\sim 6 \%$ of dietary energy. The main source of PUFA was vegetable oil. We considered together, as ( $n-3)$ fatty acids, the dietary intake of $\alpha$-linolenic acid (ALA), eicosapentaenoic acid (EPA), docosahexaenoic acid (DHA) and docosapentaenoic acid. Linoleic acid (LA) and arachidonic acid (AA) were grouped as (n-6) fatty acids. LA was the most abundant PUFA in terms of mass consumed and represented the basis for the intake of the $(n-6)$ fatty acid family, whereas AA represented only $0.12 \mathrm{~g} / \mathrm{d}$ of the total daily intake of PUFA (n-6). To test the hypothesis that dietary PUFA intake interacts with the PPARA L162V polymorphism in determining plasma lipids, we first examined total PUFA intake as a 2-category variable according to the population mean $(6 \%$ of energy). After adjustment for covariates, significant interaction terms were found only for $T G(P=0.037)$ and apoC-III $(P=0.048)$ concentrations. When PUFA intake was $\geqslant 6 \%$, TG concentrations were lower among those carrying the $162 \mathrm{~V}$ allele (122 \pm $7 \mathrm{mg} / \mathrm{dL}$ in I62V carriers vs. $136 \pm 2 \mathrm{mg} / \mathrm{dL}$ in $162 \mathrm{~L}$ homozygotes). No significant decrease of TG concentrations was found in LL homozygotes. The interaction effect in determining plasma apoC-III (Ooi et al., 2008) by PUFA category paralleled similar results for TG. Taking into account that $(n-3)$ fatty acids are specifically indicated in the treatment of hypertriglyceridemia (Kris-Etherton et al., 2002; Bays et al., 2008), we examined the specific effect for $(n-6)$ and $(n-3)$ dietary fatty acids on this genediet interaction as 2-category variables, using the population mean. Similar results were found for ( $n$ 6 ) and (n-3) fatty acids. Although little is known about the differential effect of $(n-3)$ and $(n-6)$ fatty acids on the ligand-binding activity of PPARA and specific transactivation in experimental studies, it is thought that both $(n-3)$ and $(n-6)$ can regulate the activity of PPARA. Further studies analyzing polymorphisms in the PPARA (Chan et al., 2006) or in the APOC3 (Olivieri et al., 2005) genes have reported similar diet-gene interactions with dietary PUFA in determining TG or apolipoprotein C-III concentrations.

PPARgamma (PPARG) is another member of the nuclear hormone receptor superfamily that plays an important role in the differentiation of adipocytes and in the regulation of insulin sensitivity. Several PPARG isoforms have been identified. PPARG2 is expressed predominantly in adipose tissue. The Pro12Ala polymorphism has been widely studied with highly controversial results. One of the most cited diet-gene interactions with the Pro12Ala polymorphism has been with PUFA intake. Luan et al., (2001) reported an interaction between the ratio of dietary PUFA to SFA and this polymorphism on body mass index (BMI) and fasting insulin. According to this interaction, BMI was higher among carriers of the Ala12 allele only when the PUFA/SFA ratio was low, and the opposite effect was noted in the presence of higher PUFA/SFA ratios. The same was demonstrated for fasting insulin. However, when we specifically tested this gene-nutrient interaction in the Singaporean population consisting of 1,295 Chinese, 451 Malays, and 374 Indians (Tai et al., 2004), we were not able to detect it. Our results are in agreement with those of Robitaille et al., (2003), who tested this specific interaction on BMI in the Québec Family Study and found no statistical significance. Moreover, their results were in the opposite direction from those of Luan et al., (2001).

In the Framingham Study we also found that PUFA intake interacted with the $-75 \mathrm{G} / \mathrm{A}$ polymorphism in the APOA1 gene promoter in determining HDL-C concentrations in women (Ordovas et al., 2002). Thus, having established three categories of PUFA intake (less than 4\%, from 4 to $8 \%$ and higher than $8 \%$ of total energy), we observed that the increase in PUFA intake only reduced $H D L-C$ concentrations in $G G$ individuals. However in carriers of the A allele, the HDL-C increased as PUFA in the diet increased. The separate effects of $(n-6)$ and $(n-3)$ fatty acids were not specifically investigated in this study.

Also in the Framingham Study we described a diet-gene interaction between PUFA intake and some polymorphisms in the APOA5 gene in determining TG metabolism (Lai et al., 2006). Apolipoprotein A5 is a new member of the apolipoprotein gene family whose initial discovery arose from comparative sequence analysis of the mammalian APOA1/C3/A4 gene cluster. Functional studies in mice suggested a prominent role of APOA5 in TG concentrations. Mice that overexpressed human APOA5 displayed significantly reduced $\mathrm{TG}$, whereas mice that lacked APOA5 had a large increase in plama TG (Pennacchio et al., 2003). Sequencing of the APOA5 in humans has been performed in several studies to 
identify common polymorphisms for subsequent genetic association studies. Several genetic variants have been identified (Pennacchio et al., 2003; Kluger et al., 2008). However, the most relevant are the $-1131 \mathrm{~T}>\mathrm{C}$, and the a C-to-G nonsynonymous substitution (c. $56 \mathrm{C}>\mathrm{G}$ ) that changes codon 19 from serine to tryptophan (S19W). These polymorphisms are tag SNPs of two independent haplotypes. The minor alleles of these polymorphisms have been associated with higher TG concentrations in several studies (Pennacchio et al., 2003). We analyzed the effect of PUFA consumption on plasma TG concentrations depending on the APOA5 polymorphisms (Lai et al., 2006). After multivariate control for potential confounders, a statistically significant interaction $(P<0.001)$ between SNP $-1131 \mathrm{~T}>\mathrm{C}$ and PUFA intake $(>6 \%$ or $<6 \%$ of energy) on TG concentration was found. The $-1131 \mathrm{C}$ allele was associated with an increase in fasting TG $(21 \%, P=0.002)$ only in subjects consuming $>6 \%$ of energy from PUFA. However, mean fasting TG concentrations were not statistically higher in carriers of the $-1131 \mathrm{C}$ allele compared with the TT homozygotes when the PUFA consumption was low $(<6 \%)(P=0.600)$. We observed similar and significant interactions between PUFA consumption and SNP -1131T > C on plasma remnant-like particles (RLP)-TG $(P<0.001)$ and RLP-C $(P<0.001)$. As observed for fasting TGs, concentrations of RLP. TG in subjects carrying the $-1131 \mathrm{C}$ allele were increased $(P=0.005)$ when they consumed more than $6 \%$ of energy from PUFAs. When we analyzed the interaction of SNP $-1131 \mathrm{~T}>\mathrm{C}$ and PUFA intake in determining LDL and VLDL sizes, we found statistically significant interactions $(P=0.01$ and $P=$ 0.008 , respectively). These were consistent with a more atherogenic lipid profile in subjects carrying the $-1131 \mathrm{C}$ allele and consuming more than $6 \%$ of energy from PUFAs. Thus, in carriers of the $-1131 \mathrm{C}$ allele, a high PUFA intake was associated with smaller LDL particle size and also with larger VLDL size. Using the same statistical models in which fat intake was dichotomized according to its corresponding population mean, we did not uncover any significant interactions between the APOA5 $-1131 \mathrm{~T}>\mathrm{C}$ SNP and intake of total fat, SFAs, or MUFAs on concentrations of TG, RLP-TG, or RLP-C or on LDL and VLDL particle size. This gene-diet interaction also showed a clear dose-dependent effect as well as a biologically plausible association consistent with the expected metabolic pathways involved. Moreover, the interaction observed for SNP $-1131 \mathrm{~T}>\mathrm{C}$ was not shared by SNP 56C > G, which represents the other common haplotype. Because n3 and n-6 FAs may differ in their potential preventive effect of hypertriglyceridemia (Le et al., 2007; Harris et al., 2008) we further investigated whether the PUFA-APOA5 interaction applied to the consumption of both families of PUFAs. Our results support the notion that the above-reported interactions are specific to ( $n-6)$ PUFA. The potentially negative effects associated with elevated lipoprotein remnant concentrations observed in carriers of the
APOA5 -1131C allele who consume high n-6 PUFA were not observed for the consumption of n-3 PUFA.

\section{FUTURE DIRECTIONS IN FAT-GENE INTERACTIONS}

There are many studies that have shown the existence of common genetic polymorphisms with a great impact on plasma lipid concentrations such as APOE, APOA5, CETP, PPARA, etc. Moreover, there are various studies that have shown statistical significant diet-gene interactions between some of these polymorphism and different types of fat from the diet of (total fat, PUFA, SFA, etc). Although every day more and more studies are undertaken, the level of evidence in nutrigenomics is still too low to make nutritional recommendations to the population. Thus, specifically-designed interventional as well as observational studies are needed. In addition, new bioinformatic tools will be necessary for exploiting and integrating data. Although the current evidence from both experimental and observational nutrigenetics studies is not enough to start making specific personalized nutritional recommendations of fat intake based on genetic information, the accumulated information is enticing now to show proof of concept. Hence, in a few years the "genomic" profile will be an important factor to optimize nutritional recommendations of fat intake in lipid metabolism. An important development comes from the transition of diet-gene interactions from being a purely academic research activity, to become an area of great attraction of food and health-related industries, resulting from the potential of nutrigenetics of fat intake to become one of the greatest developments for the prevention of lipid-related disorders based on a more personalized approach.

\section{ACKNOWLEDGMENTS}

This work has been partially financed by grants PI061326 and CB06/03/35 from the Instituto de Salud Carlos III, Spain.

\section{REFERENCES}

Bays HE, Tighe AP, Sadovsky R, Davidson MH. 2008. Prescription omega-3 fatty acids and their lipid effects: physiologic mechanisms of action and clinical implications. Expert. Rev. Cardiovasc. Ther. 6, 391-409.

Brunner EJ, Rees K, Ward K, Burke M, Thorogood M. 2007.Dietary advice for reducing cardiovascular risk. Cochrane Database Syst Rev.: CD002128.

Chan E, Tan CS, Deurenberg-Yap M, Chia KS, Chew SK, Tai ES. 2006. The V227A polymorphism at the PPARA locus is associated with serum lipid concentrations and modulates the lipoprotein concentrations in Chinese women. Atherosclerosis 187, 309-15. 
Chiuve SE, Willett WC. 2007. The 2005 Food Guide Pyramid: an opportunity lost? Nat. Clin. Pract. Cardiovasc. Med. 4, 610-20.

Damjanovi M, Barton M. 2008. Fat intake and cardiovascular response. Curr. Hypertens. Rep. 10, 25-31.

Getz GS, Reardon CA. 2007. Nutrition and cardiovascular disease. Arterioscler. Thromb. Vasc. Biol. 27, 24992506.

Guri AJ, Hontecillas R, Bassaganya-Riera J. 2006. Peroxisome proliferator-activated receptors: bridging metabolic syndrome with molecular nutrition. Clin. Nutr. 25, 871-885.

Harris WS, Miller M, Tighe AP, Davidson MH, Schaefer EJ. 2008. Omega-3 fatty acids and coronary heart disease risk: clinical and mechanistic perspectives. Atherosclerosis 197, 12-24.

Jump DB. 2002. Dietary polyunsaturated fatty acids and regulation of gene transcription. Curr. Opin. Lipidol. 13, 155-164.

Katan MB. 2005. The response of lipoproteins to dietary fat and cholesterol in lean and obese persons. Curr. Atheroscler Rep. 7, 460-465.

Kluger M, Heeren J, Merkel M. 2008. Apoprotein A-V: An important regulator of triglyceride metabolism. J. Inherit. Metab Dis. (in press).

Kris-Etherton PM, Harris WS, Appel LJ. 2002. Fish consumption, fish oil, omega-3 fatty acids, and cardiovascular disease. Circulation 106, 2747-2757.

Lai CQ, Corella D, Demissie S, Cupples LA, Adiconis X, Zhu Y, Parnell LD, Tucker KL, Ordovas JM. 2006 Dietary intake of $n-6$ fatty acids modulates effect of apolipoprotein A5 gene on plasma fasting triglycerides, remnant lipoprotein concentrations, and lipoprotein particle size: the Framingham Heart Study. Circulation 113, 2062-2070.

Le NA, Walter MF. 2007. The role of hypertriglyceridemia in atherosclerosis. Curr Atheroscler Rep. 9, 110-115.

Luan J, Browne PO, Harding AH, Halsall DJ, O'Rahilly S, Chatterjee VK, Wareham. 2001. Evidence for genenutrient interaction at the PPARgamma locus. Diabetes 50, 686-689.

Masson LF, McNeill G, Avenell A. 2003. Genetic variation and the lipid response to dietary intervention: a systematic review. Am. J. of Clin. Nutr. 77, 1098-1111.

Nettleton JA, Steffen LM, Ballantyne CM, Boerwinkle E, Folsom AR. 2007. Associations between HDLcholesterol and polymorphisms in hepatic lipase and lipoprotein lipase genes are modified by dietary fat intake in African American and White adults. Atherosclerosis 194, e131-140.

Olivieri O, Martinelli N, Sandri M, Bassi A, Guarini P, Trabetti E, Pizzolo F, Girelli D, Friso S, Pignatti PF, Corrocher R. 2005. Apolipoprotein C-III, n-3 polyunsaturated fatty acids, and "insulin-resistant" $T$ 455C APOC3 gene polymorphism in heart disease patients: example of gene-diet interaction. Clin. Chem. 51, 360-367.

Ooi EM, Barrett PH, Chan DC, Watts GF. 2008. Apolipoprotein C-III: understanding an emerging cardiovascular risk factor. Clin. Sci. (Lond) 114, 611624.
Ordovas JM, Corella D, Cupples LA, Demissie S, Kelleher A, Coltell O, Wilson PW, Schaefer EJ, Tucker K. 2002. Polyunsaturated fatty acids modulate the effects of the APOA1 G-A polymorphism on HDL-cholesterol concentrations in a sex-specific manner: the Framingham Study. Am. J. Clin. Nutr. 75, 38-46.

Ordovas JM, Corella D. 2004. Nutritional genomics. Annu. Rev. Genomics. Hum. Genet 5, 71-118.

Pennacchio LA, Rubin EM. 2003. Apolipoprotein A5, a newly identified gene that affects plasma triglyceride levels in humans and mice. Arterioscler. Thromb. Vasc. Biol. 23, 529-534.

Rioux V, Legrand P. 2007. Saturated fatty acids: simple molecular structures with complex cellular functions. Curr. Opin. Clin. Nutr. Metab. Care 10, 752-758.

Robitaille J, Després JP, Pérusse L, Vohl MC. 2003. The PPAR-gamma P12A polymorphism modulates the relationship between dietary fat intake and components of the metabolic syndrome: results from the Québec Family Study. Clin. Genet. 63, 109-116.

Rodriguez-Revenga L, Mila M, Rosenberg C, Lamb A, Lee C. 2007. Structural variation in the human genome: the impact of copy number variants on clinical diagnosis. Genet. Med. 9, 600-606.

Schaefer EJ, Lamon-Fava S, Ausman LM, Ordovas JM, Clevidence BA, Judd JT, Goldin BR, Woods M, Gorbach S, Lichtenstein AH. 1997. Individual variability in lipoprotein cholesterol response to National Cholesterol Education Program Step 2 diets. Am. J. Clin. Nutr. 65, 823-830.

Steinberg D. 2005. Thematic review series: the pathogenesis of atherosclerosis. An interpretive history of the cholesterol controversy: part II: the early evidence linking hypercholesterolemia to coronary disease in humans. J. Lipid. Res. 46, 179-190.

Tai ES, Corella D, Demissie S, Cupples LA, Coltell O, Schaefer EJ, Tucker KL, Ordovas JM. 2005. Framingham heart study. Polyunsaturated fatty acids interact with the PPARA-L162V polymorphism to affect plasma triglyceride and apolipoprotein C-III concentrations in the Framingham Heart Study. J. Nutr. 135, 397-403.

Tai ES, Corella D, Deurenberg-Yap M, Adiconis X, Chew SK, Tan CE, Ordovas JM. 2004. Differential effects of the C1431T and Pro12Ala PPARgamma gene variants on plasma lipids and diabetes risk in an Asian population. J. Lipid. Res. 45, 674-685.

Tai ES, Corella D, Deurenberg-Yap M, Cutter J, Chew SK, Tan CE, Ordovas JM. 2003. Singapore National Health Survey. Dietary fat interacts with the $-514 \mathrm{C}>\mathrm{T}$ polymorphism in the hepatic lipase gene promoter on plasma lipid profiles in a multiethnic Asian population: the 1998 Singapore National Health Survey. J. Nutr. 133, 3399-3408.

Zhang C, Lopez-Ridaura R, Rimm EB, Rifai N, Hunter DJ, $\mathrm{Hu}$ FB. 2005. Interactions between the $-514 \mathrm{C}->\mathrm{T}$ polymorphism of the hepatic lipase gene and lifestyle factors in relation to HDL concentrations among US diabetic men. Am. J. Clin. Nutr. 8, 1429-1435. 